\title{
Monotonic Positive Solutions of Nonlocal Boundary Value Problems for a Second-Order Functional Differential Equation
}

\author{
A. M. A. El-Sayed, ${ }^{1}$ E. M. Hamdallah, ${ }^{1}$ and Kh. W. El-kadeky ${ }^{2}$ \\ ${ }^{1}$ Faculty of Science, Alexandria University, Alexandria, Egypt \\ ${ }^{2}$ Faculty of Science, Garyounis University, Benghazi, Libya
}

Correspondence should be addressed to Kh. W. El-kadeky, k_welkadeky@yahoo.com

Received 13 October 2011; Accepted 5 December 2011

Academic Editor: István Györi

Copyright (C) 2012 A. M. A. El-Sayed et al. This is an open access article distributed under the Creative Commons Attribution License, which permits unrestricted use, distribution, and reproduction in any medium, provided the original work is properly cited.

We study the existence of at least one monotonic positive solution for the nonlocal boundary value problem of the second-order functional differential equation $x^{\prime \prime}(t)=f(t, x(\phi(t))), t \in(0,1)$, with the nonlocal condition $\sum_{k=1}^{m} a_{k} x\left(\tau_{k}\right)=x_{0}, x^{\prime}(0)+\sum_{j=1}^{n} b_{j} x^{\prime}\left(\eta_{j}\right)=x_{1}$, where $\tau_{k} \in(a, d) \subset(0,1)$, $\eta_{j} \in(c, e) \subset(0,1)$, and $x_{0}, x_{1}>0$. As an application the integral and the nonlocal conditions $\int_{a}^{d} x(t) d t=x_{0}, x^{\prime}(0)+x(e)-x(c)=x_{1}$ will be considered.

\section{Introduction}

The nonlocal boundary value problems of ordinary differential equations arise in a variety of different areas of applied mathematics and physics.

The study of nonlocal boundary value problems was initiated by Il'in and Moiseev $[1,2]$. Since then, the non-local boundary value problems have been studied by several authors. The reader is referred to [3-22] and references therein.

In most of all these papers, the authors assume that the function $f:[0,1] \times R^{+} \rightarrow R^{+}$ is continuous. They all assume that

$$
\begin{array}{ll}
\lim _{x \rightarrow \infty} \frac{f(x)}{x}=0 \quad \text { or } \infty, \\
\lim _{x \rightarrow 0} \frac{f(x)}{x}=0 \quad \text { or } \infty .
\end{array}
$$


These assumptions are restrictive, and there are many functions that do not satisfy these assumptions.

Here we assume that the function $f:[0,1] \times R^{+} \rightarrow R^{+}$is measurable in $t \in[0,1]$ for all $x \in R^{+}$and continuous in $x \in R^{+}$for almost all $t \in[0,1]$ is and there exists an integrable function $a \in L_{1}[0,1]$ and a constant $b>0$ such that

$$
|f(t, x)| \leq|a(t)|+b|x|, \quad \forall(t, x) \in[0,1] \times D .
$$

Our aim here is to study the existence of at least one monotonic positive solution for the nonlocal problem of the second-order functional differential equation

$$
x^{\prime \prime}(t)=f(t, x(\phi(t))), \quad t \in(0,1)
$$

with the nonlocal condition

$$
\sum_{k=1}^{m} a_{k} x\left(\tau_{k}\right)=x_{0}, \quad x^{\prime}(0)+\sum_{j=1}^{n} b_{j} x^{\prime}\left(\eta_{j}\right)=x_{1},
$$

where $\tau_{k} \in(a, d) \subset(0,1), \eta_{j} \in(c, e) \subset(0,1)$, and $x_{0}, x_{1}>0$.

As an application, the problem with the integral and nonlocal conditions

$$
\int_{a}^{d} x(t) d t=x_{0}, \quad x^{\prime}(0)+x(e)-x(c)=x_{1}
$$

is studied.

It must be noticed that the nonlocal conditions

$$
\begin{gathered}
x(\tau)=x_{0}, \quad \tau \in(a, d), \quad x^{\prime}(0)+x^{\prime}(\eta)=x_{1}, \quad \eta \in(c, e), \\
\sum_{k=1}^{m} a_{k} x\left(\tau_{k}\right)=0, \quad \tau_{k} \in(a, d), \quad x^{\prime}(0)+\sum_{j=1}^{n} b_{j} x^{\prime}\left(\eta_{j}\right)=0, \quad \eta_{j} \in(c, e), \\
\int_{a}^{d} x(t) d t=0, \quad x^{\prime}(0)+x(e)=x(c)
\end{gathered}
$$

are special cases of our the nonlocal and integral conditions.

\section{Integral Equation Representation}

Consider the functional differential equation (1.3) with the nonlocal condition (1.4) with the following assumptions. 
(i) $f:[0,1] \times R^{+} \rightarrow R^{+}$is measurable in $t \in[0,1]$ for all $x \in R^{+}$and continuous in $x \in R^{+}$for almost all $t \in[0,1]$ and there exists an integrable function $a \in L_{1}[0,1]$, and a constant $b>0$ such that

$$
|f(t, x)| \leq|a(t)|+b|x|, \quad \forall(t, x) \in[0,1] \times D .
$$

(ii) $\phi:(0,1) \rightarrow(0,1)$ is continuous.

(iii) $b<1 /(3-B), B=\left(\sum_{j=1}^{n} b_{j}+1\right)^{-1}$.

(iv)

$$
\sum_{k=1}^{m} a_{k}>0, \quad \forall k=1,2, \ldots, m, \quad \sum_{j=1}^{n} b_{j}>0, \quad \forall j=1,2, \ldots, n
$$

Now, we have the following Lemma.

Lemma 2.1. The solution of the nonlocal problem (1.3)-(1.4) can be expressed by the integral equation

$$
\begin{aligned}
x(t)= & A\left\{x_{0}-\sum_{k=1}^{m} a_{k} \int_{0}^{\tau_{k}}\left(\tau_{k}-s\right) f(s, x(\phi(s))) d s\right\} \\
& +B\left(t-A \sum_{k=1}^{m} a_{k} \tau_{k}\right)\left\{x_{1}-\sum_{j=1}^{n} b_{j} \int_{0}^{\eta_{j}} f(s, x(\phi(s))) d s\right\} \\
& +\int_{0}^{t}(t-s) f(s, x(\phi(s))) d s,
\end{aligned}
$$

where $A=\left(\sum_{k=1}^{m} a_{k}\right)^{-1}, B=\left(\sum_{j=1}^{n} b_{j}+1\right)^{-1}$.

Proof. Integrating (1.3), we get

$$
x^{\prime}(t)=x^{\prime}(0)+\int_{0}^{t} f(s, x(\phi(s))) d s
$$

Integrating (2.4), we obtain

$$
x(t)=x(0)+x^{\prime}(0) t+\int_{0}^{t}(t-s) f(s, x(\phi(s))) d s .
$$

Let $t=\tau_{k}$, in (2.5), we get

$$
\sum_{k=1}^{m} a_{k} x\left(\tau_{k}\right)=\sum_{k=1}^{n} a_{k} x(0)+\sum_{k=1}^{n} a_{k} \tau_{k} x^{\prime}(0)+\sum_{k=1}^{m} a_{k} \int_{0}^{\tau_{k}}\left(\tau_{k}-s\right) f(s, x(\phi(s))) d s,
$$


and we deduce that

$$
x(0)=A\left\{x_{0}-\sum_{k=1}^{m} a_{k} \tau_{k} x^{\prime}(0)-\sum_{k=1}^{m} a_{k} \int_{0}^{\tau_{k}}\left(\tau_{k}-s\right) f(s, x(\phi(s))) d s\right\}, \quad A=\left(\sum_{k=1}^{m} a_{k}\right)^{-1} .
$$

Substitute from (2.7) into (2.5), we obtain

$$
\begin{aligned}
x(t)= & A\left\{x_{0}-\sum_{k=1}^{m} a_{k} \int_{0}^{\tau_{k}}\left(\tau_{k}-s\right) f(s, x(\phi(s))) d s\right\}+x^{\prime}(0)\left(t-A \sum_{k=1}^{m} a_{k} \tau_{k}\right) \\
& +\int_{0}^{t}(t-s) f(s, x(\phi(s))) d s .
\end{aligned}
$$

Let $t=\eta_{j}$, in (2.4), we obtain

$$
\begin{gathered}
\sum_{j=1}^{n} b_{j} x^{\prime}\left(\eta_{j}\right)=\sum_{j=1}^{n} b_{j} x^{\prime}(0)+\sum_{j=1}^{n} b_{j} \int_{0}^{\eta_{j}} f(s, x(\phi(s))) d s, \\
x_{1}-x^{\prime}(0)=x^{\prime}(0) \sum_{j=1}^{n} b_{j}+\sum_{j=1}^{n} b_{j} \int_{0}^{\eta_{j}} f(s, x(\phi(s))) d s,
\end{gathered}
$$

and we deduce that

$$
x^{\prime}(0)=B\left(x_{1}-\sum_{j=1}^{n} b_{j} \int_{0}^{\eta_{j}} f(s, x(\phi(s))) d s\right), \quad B=\left(\sum_{j=1}^{n} b_{j}+1\right)^{-1} .
$$

Substitute from (2.10) into (2.8), we obtain

$$
\begin{aligned}
x(t)= & A\left\{x_{0}-\sum_{k=1}^{m} a_{k} \int_{0}^{\tau_{k}}\left(\tau_{k}-s\right) f(s, x(\phi(s))) d s\right\} \\
& +B\left(t-A \sum_{k=1}^{m} a_{k} \tau_{k}\right)\left\{x_{1}-\sum_{j=1}^{n} b_{j} \int_{0}^{\eta_{j}} f(s, x(\phi(s))) d s\right\}, \\
& +\int_{0}^{t}(t-s) f(s, x(\phi(s))) d s
\end{aligned}
$$

which proves that the solution of the nonlocal problem (1.3)-(1.4) can be expressed by the integral equation (2.3). 


\section{Existence of Solution}

We study here the existence of at least one monotonic nondecreasing solution $x \in C[0,1]$ for the integral equation (2.3).

Theorem 3.1. Assume that (i)-(iv) are satisfied. Then the nonlocal problem (1.3)-(1.4) has at least one solution $x \in C[0,1]$.

Proof. Define the subset $Q_{r} \subset C(0,1)$ by $Q_{r}=\left\{x \in C:|x(t)| \leq r, r=\left(A x_{0}+B x_{1}+(3-\right.\right.$ $B)\|a\|) /(1-(3-B) b), r>0\}$. Clear the set $Q_{r}$ which is nonempty, closed, and convex.

Let $H$ be an operator defined by

$$
\begin{aligned}
(H x)(t)= & A\left\{x_{0}-\sum_{k=1}^{m} a_{k} \int_{0}^{\tau_{k}}\left(\tau_{k}-s\right) f(s, x(\phi(s))) d s\right\} \\
& +B\left(t-A \sum_{k=1}^{m} a_{k} \tau_{k}\right)\left\{x_{1}-\sum_{j=1}^{n} b_{j} \int_{0}^{\eta_{j}} f(s, x(\phi(s))) d s\right\} \\
& +\int_{0}^{t}(t-s) f(s, x(\phi(s))) d s .
\end{aligned}
$$

Let $x \in Q_{r}$, then

$$
\begin{aligned}
|(H x)(t)| \leq & A\left\{x_{0}+\sum_{k=1}^{m} a_{k} \int_{0}^{\tau_{k}}\left(\tau_{k}-s\right)|f(s, x(\phi(s)))| d s\right\} \\
& +B\left(t-A \sum_{k=1}^{m} a_{k} \tau_{k}\right)\left\{x_{1}+\sum_{j=1}^{n} b_{j} \int_{0}^{\eta_{j}}|f(s, x(\phi(s)))| d s\right\} \\
& +\int_{0}^{t}(t-s)|f(s, x(\phi(s)))| d s \\
\leq & A\left\{x_{0}+\sum_{k=1}^{m} a_{k} \int_{0}^{1}[|a(s)|+b|x(\phi(s))|] d s\right\} \\
& +B\left\{x_{1}+\sum_{j=1}^{n} b_{j} \int_{0}^{1}[|a(s)|+b|x(\phi(s))|] d s\right\} \\
& +\int_{0}^{1}[|a(s)|+b|x(\phi(s))|] d s \\
\leq & A x_{0}+\|a\|+b \sup _{t \in I}|x(\phi(t))|+B x_{1}+B \sum_{j=1}^{n} b_{j}\|a\| \\
& +b B \sum_{j=1}^{n} b_{j} \sup |x(\phi(t))|+\|a\|+b \sup _{t \in I}|x(\phi(t))|
\end{aligned}
$$




$$
\begin{aligned}
& \leq A x_{0}+B x_{1}+2\|a\|+2 b\|x\|+(1-B)\|a\|+b(1-B)\|x\| \\
& \leq A x_{0}+B x_{1}+(3-B)\|a\|+(3-B) b r \leq r
\end{aligned}
$$

then $H: Q_{r} \rightarrow Q_{r}$ and $\{H x(t)\}$ is uniformly bounded in $Q_{r}$.

Also for $t_{1}, t_{2} \in[0,1]$ such that $t_{1}<t_{2}$, we have

$$
\begin{aligned}
(H x)\left(t_{2}\right)-(H x)\left(t_{1}\right)= & B\left(t_{2}-A \sum_{k=1}^{m} a_{k} \tau_{k}\right)\left\{x_{1}-\sum_{j=1}^{n} b_{j} \int_{0}^{\eta_{j}} f(s, x(\phi(t))) d s\right\} \\
& +\int_{0}^{t_{2}}\left(t_{2}-s\right) f(s, x(\phi(t))) d s \\
& -B\left(t_{1}-A \sum_{k=1}^{m} a_{k} \tau_{k}\right)\left\{x_{1}-\sum_{j=1}^{n} b_{j} \int_{0}^{\eta_{j}} f(s, x(\phi(t))) d s\right\} \\
& -\int_{0}^{t_{1}}\left(t_{1}-s\right) f(s, x(\phi(t))) d s \\
= & B\left(t_{2}-t_{1}\right)\left\{x_{1}-\sum_{j=1}^{n} b_{j} \int_{0}^{\eta_{j}} f(s, x(\phi(t))) d s\right\} \\
& +\int_{0}^{t_{1}}\left(t_{2}-t_{1}\right) f(s, x(\phi(t))) d s \\
& +\int_{t_{1}}^{t_{2}}\left(t_{2}-s\right) f(s, x(\phi(t))) d s .
\end{aligned}
$$

Then

$$
\begin{aligned}
\left|(H x)\left(t_{2}\right)-(H x)\left(t_{1}\right)\right| \leq & B\left|t_{2}-t_{1}\right|\left\{x_{1}+\sum_{j=1}^{n} b_{j} \int_{0}^{\eta_{j}}[|a(s)|+b|x(\phi(s))|] d s\right\} \\
& +\left|t_{2}-t_{1}\right| \int_{0}^{t_{1}}[|a(s)|+b|x(\phi(s))|] d s \\
& +\int_{t_{1}}^{t_{2}}\left(t_{2}-s\right)[|a(s)|+b|x(\phi(s))|] d s
\end{aligned}
$$


Abstract and Applied Analysis

$$
\begin{aligned}
\leq & B\left|t_{2}-t_{1}\right| x_{1}+\sum_{j=1}^{n} b_{j}[\|a\|+b r] \\
& +\left|t_{2}-t_{1}\right|[\|a\|+b r]+\int_{t_{1}}^{t_{2}}\|a\| d s+b r\left[t_{2}-t_{1}\right] .
\end{aligned}
$$

The above inequality shows that

$$
\left|(H x)\left(t_{2}\right)-(H x)\left(t_{1}\right)\right| \longrightarrow 0 \quad \text { as } t_{2} \longrightarrow t_{1}
$$

Therefore $\{H x(t)\}$ is equicontinuous. By the Arzelà-Ascoli theorem, $\{H x(t)\}$ is relatively compact.

Since all conditions of the Schauder theorem hold, then $H$ has a fixed point in $Q_{r}$ which proves the existence of at least one solution $x \in C[0,1]$ of the integral equation (2.3), where

$$
\begin{aligned}
\lim _{t \rightarrow 0^{+}} x(t)= & A\left\{x_{0}-\sum_{k=1}^{m} a_{k} \int_{0}^{\tau_{k}}\left(\tau_{k}-s\right) f(s, x(\phi(s))) d s\right\} \\
& -B A \sum_{k=1}^{m} a_{k} \tau_{k}\left\{x_{1}-\sum_{j=1}^{n} b_{j} \int_{0}^{\eta_{j}} f(s, x(\phi(s))) d s\right\}=x(0), \\
\lim _{t \rightarrow 1^{-}} x(t)= & A\left\{x_{0}-\sum_{k=1}^{m} a_{k} \int_{0}^{\tau_{k}}\left(\tau_{k}-s\right) f(s, x(\phi(s))) d s\right\} \\
& +B\left(1-A \sum_{k=1}^{m} a_{k} \tau_{k}\right)\left\{x_{1}-\sum_{j=1}^{n} b_{j} \int_{0}^{\eta_{j}} f(s, x(\phi(s))) d s\right\} \\
& +\int_{0}^{1}(1-s) f(s, x(\phi(s))) d s=x(1) .
\end{aligned}
$$

To complete the proof, we prove that the integral equation (2.3) satisfies nonlocal problem (1.3)-(1.4). Differentiating (2.3), we get

$$
\begin{gathered}
x^{\prime}(t)=B\left\{x_{1}-\sum_{j=1}^{n} b_{j} \int_{0}^{\eta_{j}} f(s, x(\phi(s))) d s\right\}+\int_{0}^{t} f(s, x(\phi(s))) d s, \\
x^{\prime \prime}(t)=f(t, x(\phi(t))) .
\end{gathered}
$$


Let $t=\tau_{k}$ in (2.3), we obtain

$$
x\left(\tau_{k}\right)=A\left\{x_{0}-\sum_{k=1}^{m} a_{k} \int_{0}^{\tau_{k}}\left(\tau_{k}-s\right) f(s, x(\phi(s))) d s\right\}+\int_{0}^{\tau_{k}}\left(\tau_{k}-s\right) f(s, x(\phi(s))) d s,
$$

which proves

$$
\sum_{k=1}^{m} a_{k} x\left(\tau_{k}\right)=x_{0}
$$

Also let $t=\eta_{j}$ in (3.7), we obtain

$$
x^{\prime}\left(\eta_{j}\right)=B\left\{x_{1}-\sum_{j=1}^{n} b_{j} \int_{0}^{\eta_{j}} f(s, x(\phi(s))) d s\right\}+\int_{0}^{\eta_{j}} f(s, x(\phi(s))) d s,
$$

then

$$
\sum_{j=1}^{n} b_{j} x^{\prime}\left(\eta_{j}\right)=B \sum_{j=1}^{n} b_{j}\left\{x_{1}-\sum_{j=1}^{n} b_{j} \int_{0}^{\eta_{j}} f(s, x(\phi(s))) d s\right\}+\sum_{j=1}^{n} b_{j} \int_{0}^{\eta_{j}} f(s, x(\phi(s))) d s .
$$

Let $t=0$ in (3.7), we obtain

$$
x^{\prime}(0)=B\left\{x_{1}-\sum_{j=1}^{n} b_{j} \int_{0}^{\eta_{j}} f(s, x(\phi(s))) d s\right\} .
$$

Adding (3.12) and (3.13), we obtain

$$
x^{\prime}(0)+\sum_{j=1}^{n} b_{j} x^{\prime}\left(\eta_{j}\right)=x_{1}
$$

This implies that there exists at least one solution $x \in C[0,1]$ of the nonlocal problem (1.3) and (1.4). This completes the proof. 
Corollary 3.2. The solution of the problem (1.3)-(1.4) is monotonic nondecreasing.

Proof. Let $t_{1}<t_{2}$, we deduce from (2.3) that

$$
\begin{aligned}
x\left(t_{1}\right)= & A\left\{x_{0}-\sum_{k=1}^{m} a_{k} \int_{0}^{\tau_{k}}\left(\tau_{k}-s\right) f(s, x(\phi(s))) d s\right\} \\
& +B\left(t_{1}-A \sum_{k=1}^{m} a_{k} \tau_{k}\right)\left\{x_{1}-\sum_{j=1}^{n} b_{j} \int_{0}^{\eta_{j}} f(s, x(\phi(s))) d s\right\} \\
& +\int_{0}^{t_{1}}\left(t_{1}-s\right) f(s, x(\phi(s))) d s \\
< & A\left\{x_{0}-\sum_{k=1}^{m} a_{k} \int_{0}^{\tau_{k}}\left(\tau_{k}-s\right) f(s, x(\phi(s))) d s\right\} \\
& +B\left(t_{2}-A \sum_{k=1}^{m} a_{k} \tau_{k}\right)\left\{x_{1}-\sum_{j=1}^{n} b_{j} \int_{0}^{\eta_{j}} f(s, x(\phi(s))) d s\right\} \\
& +\int_{0}^{t_{2}}\left(t_{2}-s\right) f(s, x(\phi(s))) d s=x\left(t_{2}\right),
\end{aligned}
$$

which proves that the solution $x$ of the problem (1.3)-(1.4) is monotonic nondecreasing.

\subsection{Positive Solution}

Let $b_{j}=0, j=1,2, \ldots n$ and $x_{1}=0$, then the nonlocal problem condition (1.4) will be

$$
\sum_{k=1}^{m} a_{k} x\left(\tau_{k}\right)=x_{0}, \quad x^{\prime}(0)=0
$$

Theorem 3.3. Let the assumptions (i)-(iv) of Theorem 3.1 be satisfied. Then the solution of the nonlocal problem (1.3)-(3.16) is positive $t \in[d, 1]$.

Proof. Let $b_{j}=0, j=1,2, \ldots n$ and $x_{1}=0$ in the integral equation (2.3) and the nonlocal condition (1.4), then the solution of the nonlocal problem (1.3)-(3.16) will be given by the integral equation

$$
x(t)=A\left\{x_{0}-\sum_{k=1}^{m} a_{k} \int_{0}^{\tau_{k}}\left(\tau_{k}-s\right) f(s, x(\phi(s))) d s\right\}+\int_{0}^{t}(t-s) f(s, x(\phi(s))) d s,
$$

where $A=\left(\sum_{k=1}^{m} a_{k}\right)^{-1}$. 
Let $t \in[d, 1]$, then

$$
\begin{gathered}
\int_{0}^{\tau_{k}}\left(\tau_{k}-s\right) f(s, x(\phi(s))) d s \leq \int_{0}^{t}(t-s) f(s, x(\phi(s))) d s, \quad \tau_{k} \leq t \\
\sum_{k=1}^{m} a_{k} \int_{0}^{\tau_{k}}\left(\tau_{k}-s\right) f(s, x(\phi(s))) d s \leq \sum_{k=1}^{m} a_{k} \int_{0}^{t}(t-s) f(s, x(\phi(s))) d s .
\end{gathered}
$$

Multiplying by $A=\left(\sum_{k=1}^{m} a_{k}\right)^{-1}$, we obtain

$$
\begin{aligned}
A \sum_{k=1}^{m} a_{k} \int_{0}^{\tau_{k}}\left(\tau_{k}-s\right) f(s, x(\phi(s))) d s & \leq A \sum_{k=1}^{m} a_{k} \int_{0}^{t}(t-s) f(s, x(\phi(s))) d s \\
& =\int_{0}^{t}(t-s) f(s, x(\phi(s))) d s,
\end{aligned}
$$

and the solution $x$ of the nonlocal problem (1.3) and (3.16), given by the integral equation (3.17), is positive for $t \in[d, 1]$. This complete the proof.

Example 3.4. Consider the nonlocal problem of the second-order functional differential equation (1.3) with two-point boundary condition

$$
x^{\prime}(0)=0, \quad x(\eta)=x_{0}, \quad \eta \in(a, d) \subset(0,1) .
$$

Applying our results here, we deduce that the two-point boundary value problem (1.3)(3.20) has at least one monotonic nondecreasing solution $x \in C[0,1]$ represented by the integral equation

$$
x(t)=x_{0}-\int_{0}^{\eta}(\eta-s) f(s, x(\phi(s))) d s+\int_{0}^{t}(t-s) f(s, x(\phi(s))) d s .
$$

This the solution is positive with $t>\eta$.

\section{Nonlocal Integral Condition}

Let $x \in C[0,1]$ be the solution of the nonlocal problem (1.3) and (1.4).

Let $a_{k}=t_{k}-t_{k-1}, \tau_{k} \in\left(t_{k-1}, t_{k}\right) \subset(a, d) \subset(0,1)$ and let $b_{j}=\xi_{j}-\xi_{j-1}, \eta_{j} \in\left(\xi_{j-1}, \xi_{j}\right) \subset$ $(c, e) \subset(0,1)$, then

$$
\sum_{k=1}^{m}\left(t_{k}-t_{k-1}\right) x\left(\tau_{k}\right)=x_{0}, \quad x^{\prime}(0)+\sum_{j=1}^{n}\left(\xi_{j}-\xi_{j-1}\right) x^{\prime}\left(\eta_{j}\right)=x_{1} .
$$


From the continuity of the solution $x$ of the nonlocal problem (1.3) and (1.4), we obtain

$$
\begin{gathered}
\lim _{m \rightarrow \infty} \sum_{k=1}^{m}\left(t_{k}-t_{k-1}\right) x\left(\tau_{k}\right)=\int_{a}^{d} x(s) d s, \\
x^{\prime}(0)+\lim _{n \rightarrow \infty} \sum_{j=1}^{n}\left(\xi_{j}-\xi_{j-1}\right) x^{\prime}\left(\eta_{j}\right)=x^{\prime}(0)+\int_{c}^{e} x^{\prime}(s) d s,
\end{gathered}
$$

and the nonlocal condition (1.4) transformed to the integral condition

$$
\int_{a}^{d} x(s) d s=x_{0}, \quad x^{\prime}(0)+x(e)-x(c)=x_{1}
$$

and the solution of the integral equation (2.3) will be

$$
\begin{aligned}
x(t)= & (d-a)^{-1}\left\{x_{0}-\int_{a}^{d} \int_{0}^{t}(t-s) f(s, x(\phi(s))) d s d t\right\} \\
& +((b-c)+1)^{-1}(t-1)\left\{x_{1}-\int_{c}^{e} \int_{0}^{t} f(s, x(\phi(s))) d s d t\right\} \\
& +\int_{0}^{t} f(s, x(\phi(s))) d s .
\end{aligned}
$$

Now, we have the following theorem.

Theorem 4.1. Let the assumptions (i)-(iv) of Theorem 3.1 be satisfied. Then the nonlocal problem

$$
\begin{gathered}
x^{\prime \prime}(t)=f(t, x(\phi(t))), \quad t \in(0,1), \\
\int_{a}^{d} x(s) d s=x_{0}, \quad x^{\prime}(0)+x(e)-x(c)=x_{1}
\end{gathered}
$$

has at least one monotonic nondecreasing solution $x \in C[0,1]$ represented by (4.4).

\section{References}

[1] V. A. Il'in and E. I. Moiseev, "A nonlocal boundary value problem of the first kind for the SturmLiouville operator in differential and difference interpretations," Differentsial'nye Uravneniya, vol. 23, no. 7, pp. 1198-1207, 1987.

[2] V. A. Il'in and E. I. Moiseev, "A nonlocal boundary value problem of the second kind for the SturmLiouville operator," Differentsial'nye Uravneniya, vol. 23, no. 8, pp. 1422-1431, 1987.

[3] Y. An, "Existence of solutions for a three-point boundary value problem at resonance," Nonlinear Analysis: Theory, Methods \& Applications, vol. 65, no. 8, pp. 1633-1643, 2006.

[4] R. F. Curtain and A. J. Pritchand, Functional Analysis in Modern Applied Mathematics, Academic Press, 1977.

[5] P. W. Eloe and Y. Gao, "The method of quasilinearization and a three-point boundary value problem," Journal of the Korean Mathematical Society, vol. 39, no. 2, pp. 319-330, 2002. 
[6] A. M. A. El-Sayed and Kh. W. Elkadeky, "Caratheodory theorem for a nonlocal problem of the differential equation $x^{\prime}=f\left(t, x^{\prime}\right)$," Alexandria Journal of Mathematics, vol. 1, no. 2, pp. 8-14, 2010.

[7] Y. Feng and S. Liu, "Existence, multiplicity and uniqueness results for a second order $m$-point boundary value problem," Bulletin of the Korean Mathematical Society, vol. 41, no. 3, pp. 483-492, 2004.

[8] K. Goebel and W. A. Kirk, Topics in Metric Fixed Point Theory, vol. 28 of Cambridge Studies in Advanced Mathematics, Cambridge University Press, Cambridge, UK, 1990.

[9] C. P. Gupta, "Solvability of a three-point nonlinear boundary value problem for a second order ordinary differential equation," Journal of Mathematical Analysis and Applications, vol. 168, no. 2, pp. 540-551, 1992.

[10] Y. Guo, Y. Ji, and J. Zhang, "Three positive solutions for a nonlinear nth-order m-point boundary value problem," Nonlinear Analysis: Theory, Methods and Applications, vol. 68, no. 11, pp. 3485-3492, 2008.

[11] G. Infante and J. R. L. Webb, "Positive solutions of some nonlocal boundary value problems," Abstract and Applied Analysis, vol. 2003, no. 18, pp. 1047-1060, 2003.

[12] A. N. Kolmogorov and S. V. Fomin, Introductory Real Analysis, Prentice-Hall, Englewood Cliffs, NJ, USA, 1970.

[13] F. Li, M. Jia, X. Liu, C. Li, and G. Li, "Existence and uniqueness of solutions of second-order threepoint boundary value problems with upper and lower solutions in the reversed order," Nonlinear Analysis: Theory, Methods \& Applications, vol. 68, no. 8, pp. 2381-2388, 2008.

[14] R. Liang, J. Peng, and J. Shen, "Positive solutions to a generalized second order three-point boundary value problem," Applied Mathematics and Computation, vol. 196, no. 2, pp. 931-940, 2008.

[15] B. Liu, "Positive solutions of a nonlinear three-point boundary value problem," Computers $\mathcal{E}$ Mathematics with Applications. An International Journal, vol. 44, no. 1-2, pp. 201-211, 2002.

[16] X. Liu, J. Qiu, and Y. Guo, "Three positive solutions for second-order $m$-point boundary value problems," Applied Mathematics and Computation, vol. 156, no. 3, pp. 733-742, 2004.

[17] R. Ma, "Positive solutions of a nonlinear three-point boundary-value problem," Electronic Journal of Differential Equations, vol. 34, pp. 1-8, 1999.

[18] R. Ma, "Multiplicity of positive solutions for second-order three-point boundary value problems," Computers \& Mathematics with Applications, vol. 40, no. 2-3, pp. 193-204, 2000.

[19] R. Ma, "Positive solutions for second-order three-point boundary value problems," Applied Mathematics Letters, vol. 14, no. 1, pp. 1-5, 2001.

[20] R. Ma and N. Castaneda, "Existence of solutions of nonlinear m-point boundary-value problems," Journal of Mathematical Analysis and Applications, vol. 256, no. 2, pp. 556-567, 2001.

[21] S. K. Ntouyas, "Nonlocal initial and boundary value problems: a survey," in Handbook of Differential Equations: Ordinary Differential Equations. Vol. II, A. Canada, P. Drabek, and A. Fonda, Eds., pp. 461557, Elsevier, Amsterdam, The Netherlands, 2005.

[22] Y. Sun and X. Zhang, "Existence of symmetric positive solutions for an m-point boundary value problem," Boundary Value Problems, vol. 2007, Article ID 79090, 14 pages, 2007. 


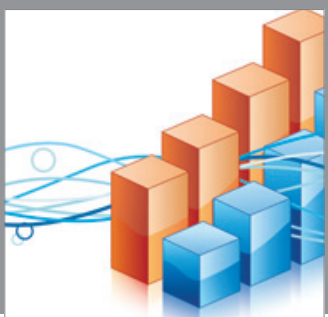

Advances in

Operations Research

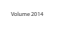

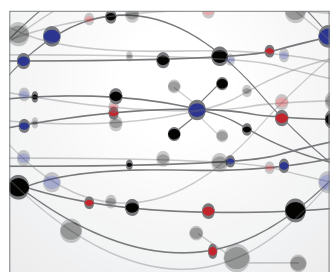

\section{The Scientific} World Journal
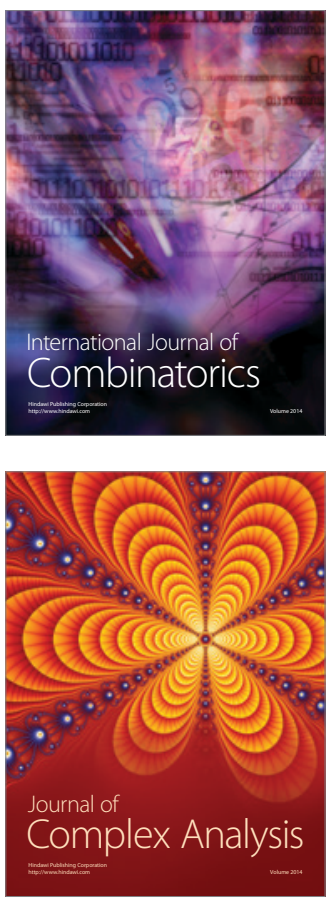

International Journal of

Mathematics and

Mathematical

Sciences
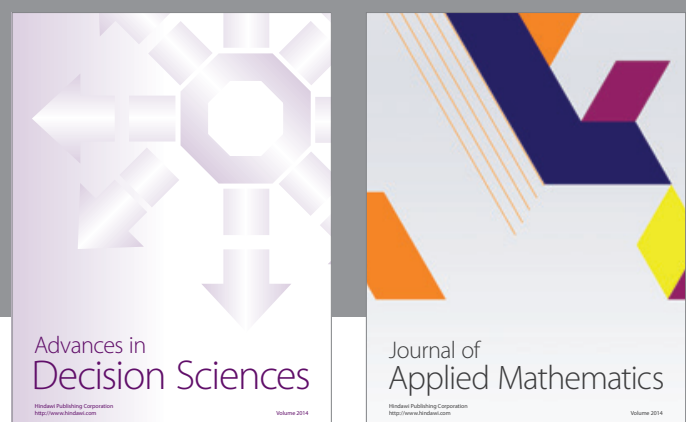

Journal of

Applied Mathematics
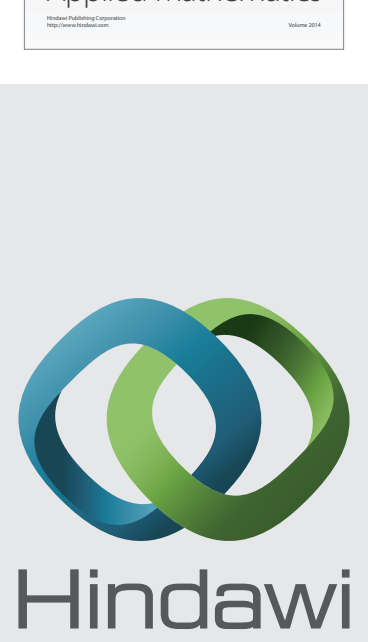

Submit your manuscripts at http://www.hindawi.com
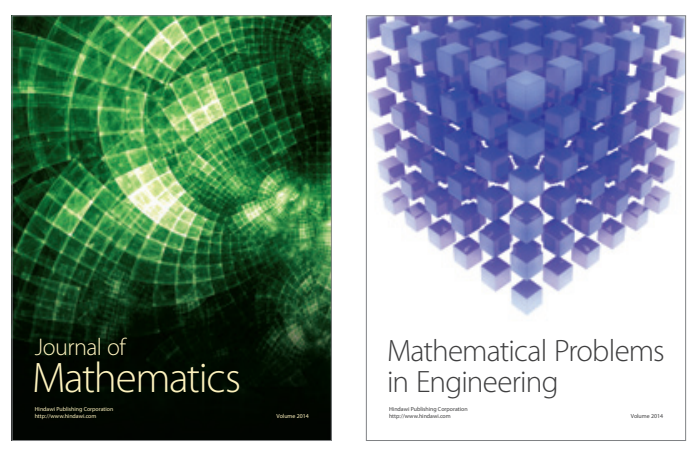

Mathematical Problems in Engineering
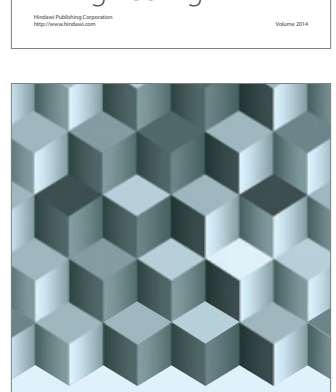

Journal of

Function Spaces
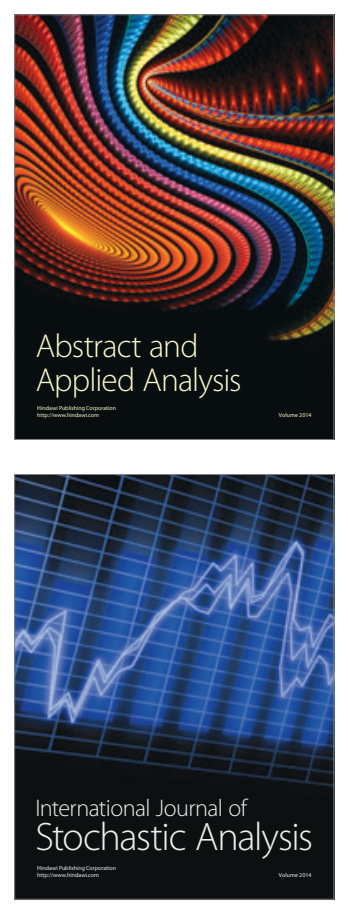

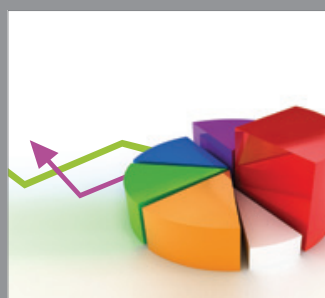

ournal of

Probability and Statistics

Promensencen
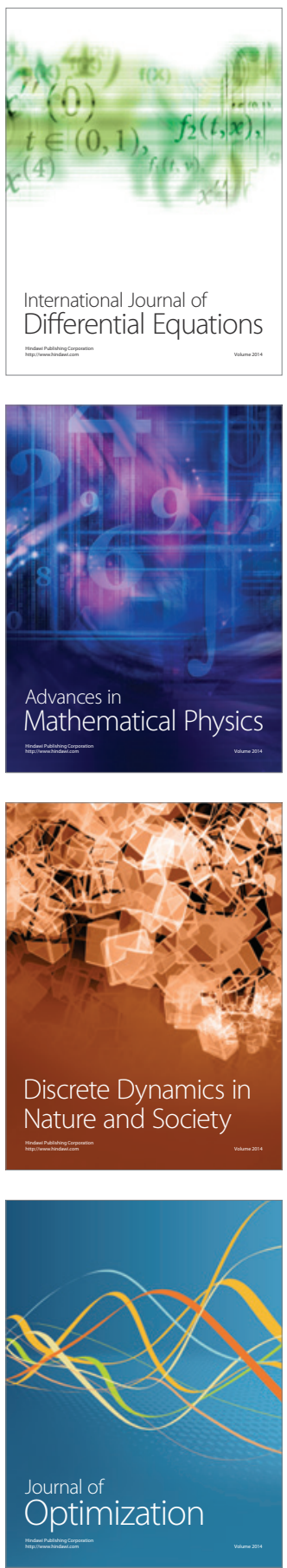